\title{
Maternal and neonatal health skills of nurses working in primary health care centre of Eastern Nepal
}

\author{
RN Chaudhary, BK Karn \\ Department of Child Health Nursing, College of Nursing \\ B.P. Koirala Institute of Health Sciences Dharan, Nepal
}

\begin{abstract}
Background: Nepal has one of the world's highest maternal and neonatal mortality. In Nepal, $73 \%$ of delivery is take place at home without trained attendant. Delivery by trained persons is $27 \%$ which reflects the need for attention of women's health in particular reproductive health. Objective: To assess knowledge and performance skills of nurses regarding maternal and neonatal health. Methods: Descriptive analytical study was carried out on nurses working in selected primary health care center of eastern region of Nepal. Random sampling technique was used to select $10 \mathrm{PHC}$ and purposive sampling technique was used to select nurses in different primary health care center. Nurses were interviewed using pre-designed questionnaire and performance skill check list. Collected data were entered in SPSS 10.5 software package and analyzed. Results: The study showed that knowledge of auxillary nurse midwife/staff nurse was satisfactory in antenatal, intra-natal and post natal care of mother while they were relatively poor in newborn resuscitation. ANM/staff nurses showed very poor skills i.e. only $16.7 \%, 36.7 \%$ and $7 \%$ were competent in providing antenatal, intra-natal and post natal care respectively. Unfortunately none were found to be competent in newborn resuscitation. Conclusion: Birth handling competence levels are generally low in ANM/Staff nurses working in PHCCs.
\end{abstract}

Key Words: Auxillary nurse midwife, staff nurse, performance skill

\section{Introduction}

One of the most daunting challenges facing the world today in the field of health is the

\section{Address for correspondence}

Ramanand Chaudhary

Additional Professor

Department of Child Health Nursing

College of Nursing

B.P. Koirala Institute of Health Sciences, Dharan

Email: ramanandachaudhary@yahoo.com issue of maternal mortality. Over the previous few decades remarkable progress has been made in almost every sector of development. More children now survive in developing countries than ever before and more of them now go to school. Unfortunately the situation in terms of maternal mortality has not 
changed much for many developing countries. It is estimated that 585,000 maternal deaths occur annually worldwide, 99 percent of this in developing countries ${ }^{1}$. The world has utterly failed to do much in this respect. This has been rightly called scandal of the century ${ }^{2}$. It is not that there is nothing that can be done. All developed countries and some in the developing world have been able to bring the maternal mortality rate down significantly. But for a vast majority of the poor countries it is a 'neglected tragedy' for effective interventions are available to deal with this persistent crisis. Reducing maternal mortality ratio by two-thirds between 1990 and 2015 is the target under the Millennium Development Goals for the international community ${ }^{3}$.

Nepal has one of the highest maternal and neonatal mortality (i.e., maternal mortality rate 539/100000 live birth, Neonatal Mortality rate $38.5 / 1000$ live birth and perinatal mortality rate 25.6/1000 live birth) in South Asia region ${ }^{4}$. The overall poor health status of women and child is due to lack of access of quality maternal and child health service especially those who are residing in rural area. In Nepal 73\% delivery takes place at home without trained attendant. Among them $67.4 \%$ maternal death occurs at home, $11.4 \%$ on the way to health facilities, $21.2 \%$ after reaching the health facilities. Delivery by trained persons is $27 \%$, which reflects the need for attention of women's health in particular reproductive health ${ }^{4}$.

High infant mortality (i.e., 64.2/1000 live birth) and neonatal mortality rate (i.e., 38.5/1000 live birth ) is also one of the important causes of the high fertility rate, which in turn, has a direct bearing on maternal morbidity and mortality. It is estimated that in Nepal, nearly 50,000 children under one year of age die every twelve months. Two third of them die within 28 days of age, resulting in over 30,000 neonatal death per year. Among those dying within the neonatal period, 20,000 (two third) die in first week of life. Nearly the same numbers of babies are still born. More than 16,000 of those dying within the first week of life die within 24 hours. As things stand, this means that three to four newborns are dying every hour in Nepal. The contributing factors to maternal neonatal death were found to be due to delay in deciding to seek care, delay in reaching care and delay in receiving care ${ }^{4}$.

\section{Methods}

Descriptive analytical study design was used to find out performance of ANM/Staff nurses on maternal and neonatal health skills. The research was conducted in selected Primary Health Centre of Ilam, Jhapa, Sunsari, Saptari and Dhankuta district. Random sampling technique was used to select 10 PHCC from five districts and purposive 
sampling technique was used to select ANM/Staff Nurses in different Primary Health Care Centre. All ANM staff nurses i.e. 30, workings in selected (sampled) PHCC were included in the study. Data was collected using structured, semi-structured questionnaire and skill check list based on the objective with simple and understandable language.

Descriptive statistics were used to analyze the data. Overall knowledge was categorized in three groups based on score obtained by each staff. One who scored $<60 \%$ in each specific area was poor while $60-80 \%$ scorers were awarded to have fair and good knowledge. Similarly for the level of competency, one who performed $>80 \%$ of required tasks as per standard set and measured by check list were considered competent in specific area of their practice. The scoring system is used by other researchers of same field ${ }^{5}$.

\section{Results}

Table 1: Characteristics of the respondents $(n=30)$

\begin{tabular}{|c|c|c|c|}
\hline S.N. & Characteristics & Frequency & $\%$ \\
\hline 1. & $\begin{array}{l}\text { Cadre } \\
\text { Staff nurse } \\
\text { Senior ANM } \\
\text { ANM }\end{array}$ & $\begin{array}{c}3 \\
4 \\
23\end{array}$ & $\begin{array}{l}10.0 \\
13.3 \\
76.7\end{array}$ \\
\hline 2. & $\begin{array}{l}\text { Age in years } \\
20-30 \\
30-40 \\
40-50 \\
>50 \\
{ }^{*} \text { Mean- } 38.46 \text { years }\end{array}$ & $\begin{array}{c}10 \\
3 \\
12 \\
5\end{array}$ & $\begin{array}{r}33.3 \\
9.9 \\
40.0 \\
16.6\end{array}$ \\
\hline 3. & $\begin{array}{l}\text { Professional education } \\
\text { Certificate nursing } \\
\text { Assistant nurse midwife }\end{array}$ & $\begin{array}{c}3 \\
27\end{array}$ & $\begin{array}{l}10.0 \\
90.0\end{array}$ \\
\hline 4. & $\begin{array}{l}\text { Experience (years) } \\
0-10 \\
10-20 \\
20-30 \\
\text { *Mean- } 16.63 \text { years }\end{array}$ & $\begin{array}{c}11 \\
4 \\
15\end{array}$ & $\begin{array}{l}36.7 \\
13.2 \\
50.1\end{array}$ \\
\hline
\end{tabular}




\begin{tabular}{|c|l|c|c|}
\hline 5. & Training received & 36.66 \\
& Midwifery refresher training & 11 & 3.33 \\
Emergency obstetric care & 1 & 3.33 \\
Basic obstetric care & 1 & 13.33 \\
Reproductive health & 4 & 6.66 \\
Post abortion care & 2 & 6.66 \\
Comprehensive family planning & 2 & 10 \\
\hline
\end{tabular}

Table 2: Distribution of respondents by self reported services attended per week and type of services $(n=30)$

\begin{tabular}{|c|c|c|c|}
\hline \multirow{2}{*}{ S.N. } & \multirow{2}{*}{ Type of service } & \multicolumn{2}{|c|}{ ANM staff nurses } \\
\hline & & No. & $\%$ \\
\hline 1. & $\begin{array}{l}\text { ANC attended per week } \\
0-10 \\
11-20 \\
21-30 \\
31 \text { and over } \\
\text { Mean: } 32.93\end{array}$ & $\begin{array}{c}3 \\
6 \\
13 \\
8\end{array}$ & $\begin{array}{c}10 \\
20 \\
43.33 \\
26.66\end{array}$ \\
\hline 2. & $\begin{array}{l}\text { Births attended per week } \\
1 \\
2 \\
3 \\
\text { Mean: } 2.83\end{array}$ & $\begin{array}{c}17 \\
10 \\
3\end{array}$ & $\begin{array}{c}56.66 \\
33.33 \\
10\end{array}$ \\
\hline 3. & $\begin{array}{l}\text { PNC attended per week } \\
0-5 \\
5-10 \\
\text { Mean: } 2.16\end{array}$ & $\begin{array}{c}25 \\
5\end{array}$ & $\begin{array}{l}83.33 \\
16.66\end{array}$ \\
\hline
\end{tabular}

Table 3: Distribution of the respondents by the type of problems/issues $(n=30)$

\begin{tabular}{|c|l|c|c|}
\hline S.N. & \multicolumn{1}{|c|}{ Problem/issue } & No. & $\%$ \\
\hline 1. & Inadequate refresher training related to midwifery & 27 & 90 \\
\hline 2. & Lack of proper supplies ( equipments/drugs) & 30 & 100 \\
\hline
\end{tabular}




\begin{tabular}{|c|l|c|c|}
\hline 3. & Lack of proper accommodation and security & 25 & 83.33 \\
\hline 4. & Inadequate monitoring and evaluation & 28 & 93.33 \\
\hline
\end{tabular}

Table 4: Distribution of respondent's overall knowledge score $(n=30)$

\begin{tabular}{|c|c|c|c|c|c|c|c|c|}
\hline \multirow[t]{2}{*}{ S.N. } & \multirow[t]{2}{*}{ Knowledge } & \multicolumn{2}{|c|}{$\begin{array}{c}\text { Poor } \\
(<60 \%)\end{array}$} & \multicolumn{2}{|c|}{$\begin{array}{c}\text { Fair } \\
(60-80 \%)\end{array}$} & \multicolumn{2}{|c|}{$\begin{array}{l}\text { Good } \\
(\geq 80 \%)\end{array}$} & \multirow[t]{2}{*}{ Remarks } \\
\hline & & No. & $\%$ & No. & $\%$ & No. & $\%$ & \\
\hline 1. & $\begin{array}{l}\text { Antenatal history, } \\
\text { physical examination } \\
\text { and basic care }\end{array}$ & 1 & 3.33 & 20 & 66.66 & 9 & 30 & Mean: 75.1 \\
\hline 2. & $\begin{array}{l}\text { Normal labor, child } \\
\text { birth and immediate } \\
\text { newborn care }\end{array}$ & 0 & 0 & 15 & 50 & 15 & 50 & Mean: 78.17 \\
\hline 3. & $\begin{array}{l}\text { Post partum, history, } \\
\text { physical examination } \\
\text { (mother and baby), and } \\
\text { basic care }\end{array}$ & 1 & 3.33 & 26 & 86.58 & 3 & 10 & Mean: 70.1 \\
\hline 4. & Newborn resuscitation & 6 & 20 & 20 & 66.66 & 4 & 13.33 & Mean: 69.76 \\
\hline
\end{tabular}

Table 5: Maternal and newborn skills assessed during supervision by assessment tool $(n=30)$

\begin{tabular}{|l|l|c|c|c|c|}
\hline \multirow{2}{*}{ S.N. } & \multicolumn{1}{|c|}{ Skills } & \multicolumn{2}{|c|}{$\begin{array}{c}\text { In anatomical } \\
\text { model }\end{array}$} & \multicolumn{2}{c|}{ In woman } \\
\cline { 3 - 6 } & & No. & $\%$ & No. & $\%$ \\
\hline 1. & $\begin{array}{l}\text { Antenatal history, physical examination and basic } \\
\text { care }\end{array}$ & 0 & 0 & 30 & 100 \\
\hline 2. & $\begin{array}{l}\text { Normal labor, child birth and immediate newborn } \\
\text { care }\end{array}$ & 28 & 93.34 & 2 & 6.66 \\
\hline 3. & $\begin{array}{l}\text { Post partum history, physical examination } \\
\text { (Mother and Baby), and basic care }\end{array}$ & 0 & 0 & 30 & 100 \\
\hline 4. & Newborn resuscitation & 30 & 100 & 0 & 0 \\
\hline
\end{tabular}


Table 6: Nurse assessed as competent in essential maternal and neonatal health skills $(n=30)$

\begin{tabular}{|c|l|c|c|c|c|}
\hline \multirow{2}{*}{ S.N. } & \multicolumn{1}{|c|}{ Skills } & \multicolumn{4}{|c|}{ Competent } \\
\cline { 3 - 6 } & & Yes & $\%$ & No & $\%$ \\
\hline 1. & $\begin{array}{l}\text { Antenatal history, physical } \\
\text { examination and basic care }\end{array}$ & 5 & 16.7 & 25 & 83.3 \\
\hline 2. & $\begin{array}{l}\text { Normal labor, child birth and } \\
\text { immediate newborn care }\end{array}$ & 11 & 36.7 & 19 & 63.3 \\
\hline 3. & $\begin{array}{l}\text { Post partum history, physical } \\
\text { examination (mother and baby), } \\
\text { and Basic care }\end{array}$ & 2 & 6.7 & 28 & 93.3 \\
\hline 4. & Newborn resuscitation & 0 & 0 & 30 & 100.0 \\
\hline
\end{tabular}

\section{Discussion}

Nepal is multiracial, multicultural country and has varied disparities on ecological pattern. In such case no single, localize study can claim to represent the whole country. Pregnancy related deaths and disabilities result not only in human suffering but also in losses to social and economic development. The women who die are in the prime of life, responsible for the health and well-being of their families. They generate income, grow and prepare food, educate the young, and care for children, elderly and the sick. Their deaths represent a drain on all development efforts. Pregnancy is not a disease, and pregnancy related mortality and morbidity are preventable with attainable, simple and cost effective interventions. Failure to do so is to deny women a fundamental human right - the right to the highest attainable level of health.

Based on the background characteristics of population, majority of them were ANM $(76.6 \%)$. Thus majority of people who are utilizing the services of PHCC are directly served by ANMs. Among all ANM staff nurses $90 \%$ were married, with mean age of 38.46 years, $100 \%$ had professional education, and $50.1 \%$ had job experience of $20-30$ years with mean duration of 16.63 years. Most of them had some kind of training in $\mathrm{MCH}$ including maximum of $36.66 \%$ MRT. Therefore we claim to have experienced health workers serving our people in the periphery.

According to the self reported service attended by nurses, each and every representative were found to be involved in 
$\mathrm{MCH}$ activities especially 43.33\% were attending 21 - 30 antenatal mothers, 55.66\% had an opportunity to conduct a delivery at PHCC and majority were involved in providing postnatal care to the mothers. Though the number of delivery conducted at PHCC and services to the post natal mother seem to be lesser than expected, it is not because health workers who are not willing to extend their care rather very few mothers are coming for delivery and postnatal services.

Based on the finding related to over all knowledge score in various areas, majority of ANM/ Staff Nurses (66.66\%) had fair knowledge of antenatal care, $50 \%$ had good knowledge regarding child birth and immediate new born care, $86.58 \%$ had fair knowledge about post partum care and $66.66 \%$ fair knowledge about newborn resuscitation. As per assessment of skills, $100 \%$ of the respondents demonstrated their skills on antenatal and postnatal mothers.

Knowledge is the back bone of skill \& practice. While assessing the knowledge about antenatal care, history taking and physical examination were focused. Our findings showed that $66.66 \%$ ANM/Staff Nurses had fair knowledge, 30\% had good knowledge and only $3.33 \%$ had poor knowledge about antenatal care. As ANM Staff Nurses working at PHCC get frequent opportunity for antenatal care this might have contributed to their knowledge.
The study revealed that 50\% ANM/Staff Nurses at PHCC had fair and rest $50 \%$ had good knowledge about normal labor. Though opportunities for caring mothers in labor are least at PHCC, ANM and staff nurses had good knowledge. This might have appeared because they have more interest in intranatal events and care. Being less frequently involved in relatively high risky practice, intranatal care might have got extra attention by ANM Staff/Nurses. In reference to knowledge about postnatal care $86.58 \%$ ANM Staff/Nurses had fair knowledge while 10\% had good knowledge. Even though they had more opportunity to interact with postnatal mothers in compare to intranatal mothers, the knowledge of ANM/Staff Nurses were more about intranatal events and their care. This is significantly similar finding conducted by Harvey SA et al. (2007) in which knowledge score in Nicaragua was $74 \%$; the mean skills score was $46 \%$. Similarly, the mean knowledge score on management of postpartum haemorrhage was $63 \%$; the skills scores for manual removal of the placenta and bimanual uterine compression - basic evidence-based interventions to control postpartum haemorrhage - were $41 \%$ and $22 \%$ respectively ${ }^{3}$.

Newborn care is essential component of $\mathrm{MCH}$ care. The study showed that $66.66 \%$ respondents had fair knowledge, 13.33\% had good knowledge and $20 \%$ had poor 
knowledge regarding newborn resuscitation. In comparison with antenatal, intranatal, postnatal knowledge about newborn resuscitation was least among all. The reason behind compromised status of knowledge regarding newborn resuscitation among ANM Staff Nurses might be an inadequate opportunity to resuscitate the newborn baby at PHCC.

Skills of ANM/Staff Nurses working at various PHCC of eastern region of Nepal were assessed on pregnant mothers at real clinic set up and anatomical model. All ANM Staff Nurses had opportunity to demonstrate their skill about antenatal \& postnatal care on pregnant mother at PHCC while only $6.66 \%$ had opportunity to show their skills of intranatal care in actual situation, rest $93.33 \%$ on anatomical model. Similarly all ANM/Staff Nurses demonstrated their skills for newborn resuscitation on anatomical model.

While providing antenatal care to the mothers, $83.3 \%$ ANM/Staff Nurses were incompetent. The finding is similar with the finding of the study conducted by Carlough $\mathrm{M}$ et al. in which majority of nurses were not competent in providing atenatal care ${ }^{1}$. The fact might have appeared because health workers do not find it essential to provide complete comprehensive antenatal care and tend to escape several components. Similarly, 63.3\% ANM/Staff Nurses were incompetent to conduct normal delivery at PHCC. The particular findings might be because ANM/Staff Nurses have less opportunity to conduct delivery at PHCC. Another reason for the same might be the traditional techniques of conducting delivery which they are not able to eliminate from their practice despite they have good knowledge.

The study did not find any one individual competent for providing newborn resuscitation. Unfortunately most of the PHCC were lacking resuscitation equipments at clinic; some of the ANM Staff Nurses had never used those equipments and few were not able to recognize $A M B U$ bag. Thus it appeared to be an immediate concern for all of us.

\section{Conclusion}

Results indicate that maternal and neonatal health care competence levels are generally low. Key life-saving skills, active management of $3^{\text {rd }}$ stage labor, bimanual uterine compression, and newborn resuscitation are rarely performed. While our competency measurement instruments worked well in general, they need some refinement before they could be applied on a large scale. Both knowledge and skills tests should be shortened. A group of expert clinicians (doctors and nurses) should be employed to help fine-tune measurement methods. Senior clinicians and health program managers in 
our country could apply these methods without assistance from international consultants, but anatomical models should be available at the district or health facility level. Appropriately refined, our methods for measuring skilled birth attendant competence could help improve targeting of scarce training and supervisory resources. They could also serve as one key component of a more comprehensive effort to improve quality of maternal and neonatal health care in our country settings.

\section{References}

1. World Health Organization. Maternal Mortality. Available from htp://www.who.int/ media centre/factsheets/fs348/en/index.html (Media Centre 2012).

2. Harvey SA, Ayabaca P, Boucar M. et al. Are skilled birth attendants really skilled? A multi-country study of SBA competence. Bulletin of the World Health Organization. 2007; 85 (10): 100-7.

3. World Health Organization. Reproductive Health Indicators: Guidelines for Their Generation and Analysis for Global Monitoring. World Health Organization: 2011; Geneva 27, Switzerland.

4. Nepal Demographic Health Survey (2011). Population Division Ministry of
Health and Population, Government of Nepal.

5. McDonald M, Starrs A. The essential competencies of a skilled birth attendant. Skilled care during childbirth. Information Booklet. Family Care International (FCI), New York; 2002

6. JHPIEGO/Maternal and Neonatal Health Program. Guidelines for assessment of skilled providers after training in maternal and newborn health care. 2004; 1- 134.

7. Carlough M, McCall M. Skilled birth attendance: what does it mean and how can it be measured? A clinical skills assessment of maternal and child health workers in Nepal. International $\mathrm{J}$ Gynaecol Obstet. 2005; 89(2):200-8.

8. Harvey SA, Ayabaca P, Bucagu M. et al. Skilled birth attendant competence: an initial assessment in four countries, and implications for the Safe Motherhood movement. International $\mathrm{J}$ of Gynaecol Obstet. 2004; 87(2): 20310.

9. World Health Organization. Making pregnancy safer (MPR): skilled attendants. WHO website.www.who.int/reproductivehealth/mpr/attendants.html.

10. Report on post refresher training followup of $\mathrm{MCH}$ workers conducted by the regional field officers of HMG/UNFPA 
program support unit in selected

districts during July-September 2001. NHTC. October 2001.

11. Graham W, Bell JS, Bullough CHW. Can skilled attendance at delivery reduce maternal mortality in developing countries? Stud. HSO\&P. 2001; 17: 97-129

12. Shakya G. Abortion Law in Nepal Women's Right to Life and Health: Reproductive Health Matters. 2004; 12 : 75-84.

13. Nepal Family Health Program, A midterm survey for NFHP II: Family Planning, Maternal, Newborn and Child
Health situation in rural Nepal. Nepal Family Health Program II and New ERA, 2010, Family Planning; p-17.

14. Maternal Mortality and Morbidity Survey: Summery of Preliminary Key Findings of 2008/2009. Kathmandu, Nepal: Nepal Maternal Mortality and Morbidity Study, Government of Nepal, Ministry of Health and Population, Department of Health Services, Family Health Division;

15. Tuladhar $H$, Dali SM, Pradhananga V. Complication of home delivery, a retrospective analysis. J Nepal Med Association 2005; 44(159):87-91. 